\title{
Communication as the crucial link: Toward a multilevel approach to normative social influence
}

\author{
Sarah Geber*, University of Zurich, Department of Communication and Media Research IKMZ, \\ Switzerland \\ Erica Sedlander, University of California, San Francisco, Department of Family and Community \\ Medicine, United States \\ ${ }^{*}$ Corresponding author: s.geber@ikmz.uzh.ch
}

\begin{abstract}
Social norms are informal rules within a group or society. Despite the consensus that social norms affect behavior, there is an inherent tension in the cross-disciplinary norms literature between the conceptualization of norms as individual and collective phenomena. The present paper capitalizes on the potential of communication as the link between different levels of social norms to develop an integrative approach to normative social influences. Concretely, it refers to the differentiation between perceived and collective norms, systematizes the current literature on the role of communication in social normative influences, and outlines how communication serves as functional link between the individual and collective level of norms. The resulting multilevel approach to normative social influences (MANSI) allows us to reflect on norms as dynamic phenomena that account for individual and social change. Ultimately, we discuss challenges and areas for further inquiry for the study of norms, and thereby derive recommendations for future research on multilevel normative social influences.
\end{abstract}

\section{Keywords}

perceived norms, collective norms, multilevel approach, communication processes, cross-level link, social change

\section{Introduction}

Social norms are informal rules within a group or society "that either prescribe or proscribe behaviors that members of a group can enact" (Rimal \& Real, 2003, p. 185). In contrast to laws (Carbonara, 2017), they are not legally but socially enforced and are not explicitly codified but understood and created through social interaction (Hechter \& Opp, 2001b). Thus, the study of norms and their influences "is a study of human interactions" (Chung \& Rimal, 2016, p. 3), which is why various disciplines in the social sciences have developed an area of scholarship that focuses on normative aspects (Chung \& Rimal, 2016; Legros \& Cislaghi, 2020).

While the cross-disciplinary social norms literature agrees on the vital behavioral relevance of social norms, there is also some disagreement on whether social norms are individual or collective constructs, thus, whether they are psychological states or properties of social entities (Legros \& Cislaghi, 2020). Both understandings of social norms have their benefits, depending on the field's perspective and primary interest (Legros \& Cislaghi, 2020). A comprehensive understanding of the reciprocal relationship between individual and social change, however, requires an approach that integrates the individual and collective conceptualization of norms and, thus, acknowledges that individuals are affected by their environment's norms and, on the other hand, reshape their normative environment through their actions (Coleman, 1986b; Latané, 1996).

The communication field "has much to contribute" to such an integrative approach (Yanovitzky \& Rimal, 2006, p. 2), as communication plays a crucial role in forming normative perceptions and disseminating norms in social groups (e.g., 
Geber \& Hefner, 2019; Rimal \& Lapinski, 2015). The present paper systematizes the current literature on the role of communication in social normative influences and underlines how communication serves as link between the individual and collective level of norms. It thereby considers various forms of communication in the contemporary media environment, such as mass media, social media, and personal communication. The resulting multilevel approach to normative social influences (MANSI) with communication as the cross-level link is used to reflect on norms as dynamic phenomena and to provide preliminary explanations for individual- and group-level changes (Tankard \& Paluck, 2016).

Our mission in creating the MANSI is to provide a framework that inspires future research to go beyond individual-level approaches in order to cope with the complexity of social reality and to better understand individual behavior. This is all the more relevant as studies in the fields of psychology and communication treat social norms mainly as individual-level attributes (Shulman et al., 2017). Further, the approach is relevant to applied research as it provides an important framework for communication interventions that target mechanisms of change at different levels to improve behaviors, such as health and risk behaviors (Sallis \& Owen, 2015; Sedlander et al., 2020).

\section{Social norms}

The concept of social norms is discussed among others in social psychology (Deutsch \& Gerard, 1955; Sherif, 1936), public health (Edberg \& Krieger, 2020; Perkins \& Berkowitz, 1986), philosophy (Bicchieri, 2005), economics (Young, 1998), sociology (Parsons, 1951), and communication (Yanovitzky \& Rimal, 2006; for an overview: Legros \& Cislaghi, 2020). Despite distinct approaches to understanding norms, there is a certain overlap in the conceptualization of norms, especially in the fields of psychology, public health, and communication (Chung \& Rimal, 2016).

\subsection{Descriptive and injunctive norms}

Social norms can be differentiated with regard to whether they are descriptive or injunctive - a distinction that has been established in the seminal work on normative conduct by Cialdini, Reno and Kallgren (1990). Descriptive norms describe what is done by most people, that is, "what is typical or normal" within a reference group (Cialdini et al., 1990, p. 1015). As descriptive norms reveal which behaviors are prevalent, they are also referred to as "behavioral norms" (Perkins, 2002, p. 165). Injunctive norms, on the other hand, specify what ought to be done and refer to the social approval of a certain behavior among referent others (Cialdini et al., 1990). They are also referred to as "attitudinal norms" (Perkins, 2002, p. 164) because they convey evaluations that other people have of certain acts.

People are especially motivated to follow the norms of groups they belong to or aspire to belong to, known as "reference groups" (Merton \& Rossi, 1968; Saxena, 1971; Sherif, 1953). Thus, a reference group refers to relevant others whose behavior and (dis)approval matter to an individual in a specific situation and thereby are turned to as a standard or "frame of reference” (Merton \& Rossi, 1968, p. 258) that provide orientation to the individual (Legros \& Cislaghi, 2020). Reference groups may include proximal groups (such as close friends or family) and more distal referent others (such as schoolmates or colleagues); they may relate to clearly defined smaller groups of people, as the family, but also to more abstract collectives, such as societies and cultures (Hechter \& Opp, 2001a; Patrick, Neighbors, \& Lee, 2012).

\subsection{Perceived and collective norms}

As group phenomena that provide orientation for individuals, social norms exist as both perceived and collective norms (Table 1). Perceived and collective norms differ according to the level to which they pertain, as explicated by Lapinski and Rimal (2005; Rimal \& Lapinski, 2015). Perceived norms are located at the individual, psychological level and represent individual's perceptions of the reference group's 
Table 1: Descriptive and injunctive norms as perceived and collective norms

\begin{tabular}{lll}
\hline & Descriptive norms & Injunctive norms \\
\hline $\begin{array}{l}\text { Perceived norms } \\
\text { (Individual level) }\end{array}$ & $\begin{array}{l}\text { Perceived descriptive norms } \\
\text { Individual's perceptions about the } \\
\text { referent group's behavior }\end{array}$ & $\begin{array}{l}\text { Perceived injunctive norms } \\
\text { Individual's perceptions about the } \\
\text { referent group's approval of the behavior }\end{array}$ \\
$\begin{array}{l}\text { Collective norms } \\
\text { Group level) }\end{array}$ & $\begin{array}{l}\text { Collective descriptive norms } \\
\text { The referent group's behavior }\end{array}$ & $\begin{array}{l}\text { Collective injunctive norms } \\
\text { The referent group's attitude } \\
\text { toward the behavior }\end{array}$ \\
\hline
\end{tabular}

Note: Taxonomy based on Lapinski and Rimal (2005) as well as Rimal and Lapinski (2015), see also Geber et al. (2021).

norms. In contrast, collective norms operate at the level of the reference group and "represent a collective social entity's code of conduct" (Lapinski \& Rimal, 2005, p. 129). To contrast them with subjective perceptions, collective norms are also referred to as "actual norms" (Berkowitz, 2004) or - in order to underline the level to which they pertain - as "group norms" (Hogg \& Reid, 2006).

Both facets of norms, descriptive and injunctive, can be conceptualized as perceived and collective norms (Lapinski \& Rimal, 2005; Rimal \& Lapinski, 2015; also Geber, Baumann, Czerwinski, \& Klimmt, 2021). Concretely, perceived descriptive norms refer to the perceived prevalence, and perceived injunctive norms refer to the perceived social approval of the behavior within the reference group. At the group level, collective descriptive norms pertain to the referents' actual behavior and, thus, the actual prevalence of a behavior within the collective. Collective injunctive norms, on the other hand, are also defined as "regularities in attitudes” (Hogg \& Reid, 2006, p. 7) and pertain to the referents' actual social approval of a given behavior and thus to the collective's attitudes toward it.

\section{A multilevel approach to normative social influences (MANSI)}

The differentiation between perceived and collective norms leads to the questions of how collective norms are linked with perceived norms, how collective norms exert influence on individual behavior, and, ultimately, how norms on both levels change over time. The basic answer to these questions is lying in the central idea that social norms are "communicative phenomena" (Geber \& Hefner, 2019; also Hogg \& Reid, 2006; Real \& Rimal, 2007). Norms "cannot exist in the absence of communication among members of the group" (Rimal \& Real, 2003, p. 185); they are constructed, understood, and negotiated through communication (Carcioppolo \& Jensen, 2012, p. 767). At the same time, communication is a fundamental aspect of social relationships (Valente, 2005; Yanovitzky \& Rimal, 2006).

\subsection{The micro-macro-scheme}

To develop a multilevel approach to normative social influences (MANSI, Figure 1) that links individual normative perceptions with collective norms, we borrow from Coleman (1986b) the micro-macro-scheme. This scheme is "the standard tool for representing micro-macro models" (Raub, Buskens, \& van Assen, 2011, p. 2, see also Opp, 2011). It differentiates between two levels - micro and macro and conceptualizes cross-level links between both levels. In Coleman's terminology, "macro" refers to collectives such as a family, a school, or a society (Coleman, 1986a, p. 346), whereas "micro" refers to individuals. The cross-level links include empirical "bridge assumptions" for the macro-to-micro relation as well as analytical "transformation rules" such as definitions for the micro-to-macro relation (Raub et al., 2011, p. 4). The micro-macro-scheme is especially appropriate to gain a multilevel understanding of normative social influences that addresses the crucial role of communication. First, the scheme is compatible with the basic differentiation of Lapinski and Rimal (2005; Rimal \& Lapinski, 2015) between perceived norms 
Figure 1: Multilevel approach to normative social influences (MANSI) with communication as the cross-level link

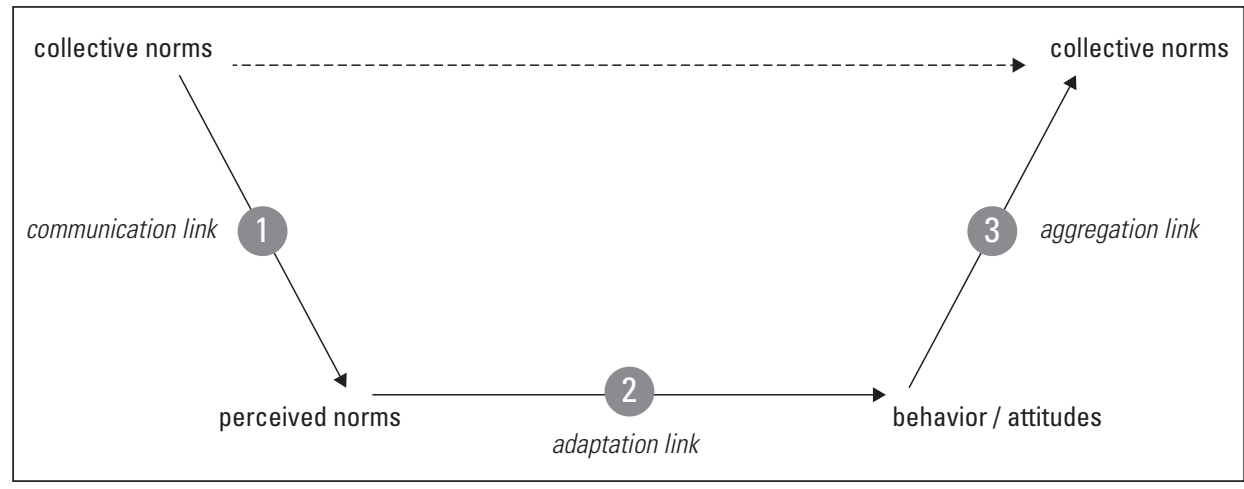

at the micro level and collective norms at the macro level (Geber et al., 2021). Second, and more importantly, the scheme will allow us to connect both levels and to present a coherent multilevel approach in the following sections by (1) outlining communication as the bridge assumption for the macro-to-micro relation (Link \#1); (2) integrating current behavioral theories that provide assumptions on norms-based regularities of individual behavior, such as the theory of normative social behavior (Link \#2); and (3) presenting aggregation as the "transformation rule" that links individual attributes at the micro level with collective norms at the macro level (Link \#3). Figure 1 displays the MANSI that implies three links, to be derived in the following chapters.

\subsection{Link \# 1: Communication link}

The first link (\#1, communication link) of our multilevel approach to normative social influences refers to communication as cross-level link and addresses the question of how collective norms are linked to individual normative perceptions. We thereby consider different forms of communication in the contemporary media environment. Concretely, by communication, we refer to offline (face-to-face) and online social interactions between people (Berger, 2008), as well as media exposure to normative messages that are produced and disseminated by institutional and professional media sources (Nagler, 2017).
First, as norms refer to the behavior and attitudes within a reference group, communication with group members convey important normative information (Geber, Baumann, \& Klimmt, 2019; Mead, Rimal, Ferrence, \& Cohen, 2014). This communication can be more or less explicit: Group members can express what is and what is not normative in the group, by reporting their behavior in talk, by talking about whether a certain behavior is socially approved, or by presenting norms in terms of stories that provide indirect accounts for what is and what should be (Hogg \& Reid, 2006; also Fine, 2001). Further, injunctive information of approval or disapproval might also be transmitted by non-verbal communication, such as gestures and facial expressions (Burgoon \& Buller, 1996). On the basis of this communication, individuals infer the norms of the respective group with regard to what is done within the group (perceived descriptive norms) and what ought to be done (perceived injunctive norms). These processes of norm formation have been demonstrated, among others, for the case of risk behaviors among adolescents and young adults. In a study on speeding in road traffic, Geber et al. (2019) showed that normative perceptions toward risky driving behavior did not only depend on the frequency of peer communication but also on communication's topics. The more young drivers talked about topics that positively evaluate risk-taking, such as the 
fun of speeding, the more they perceived that speeding was prevalent and socially approved among their friends. Comparably, a study of Hendriks, Scholz, Larsen, Bruijn, and van den Putte (2021) revealed that a more positive perceived conversational valence about alcohol and binge drinking was related to perceptions of more positive binge drinking norms among college students.

Additionally, referring to social cognitive theory (Bandura, 1986), observational learning is considered as a further process leading to normative perceptions (Geber \& Hefner, 2019). Group members serve as relevant models; they draw attention and are observed. Observations of social referents' behaviors result in the belief of the prevalence of a behavior (perceived descriptive norms) and observed reactions of others lead to the belief of social approval or disapproval for the behavior (perceived injunctive norms). In line with this argument, Kashima, Wilson, Lusher, Pearson, and Pearson (2013) studied norms in a rural city in Australia and found that norms and community engagement were acquired experientially, that is, by observing what their associates do. Comparably, a study among a vegetarian co-operative on a university campus showed that normative perceptions about meat consumptions and activism were shaped by recurring patterns of interaction (Shepherd, 2017; also Paluck \& Shepherd, 2012).

Digitalization allows for such interpersonal interactions to take place faceto-face as well as digitally (Guadagno, Muscanell, Rice, \& Roberts, 2013; Walther et al., 2010). On social media, where people are connected with referent others, images present what their referent others do (descriptive norms), and popularity cues on social media (Haim, Kümpel, \& Brosius, 2018) can be regarded as a metric representation of social approval (injunctive norms). We note that different popularity cues (e.g., likes, shares) might have different connotations that also vary across platforms; nevertheless, it is notable that they comprise easily accessible normative information (Geber \& Hefner, 2019) and that they become more and more important for individual orientation (Porten-Chée, Hassler, Jost, Eilders, \& Maurer, 2018). In line with this argument, a study of Pempek, Yermolayeva, and Calvert (2009) showed that students spend much of their time reading and viewing information about their peers on Facebook. Further studies, such as an experimental study by Litt and Stock (2011) or surveys by Beullens and colleagues (Beullens \& Vandenbosch, 2016; Geusens, Bigman-Galimore, \& Beullens, 2020) demonstrated the importance of social media platforms in the formation process of drinking norms. Adolescents who were more frequently exposed to alcohol-related content perceived alcohol consumption to be more prevalent and socially approved among their friends (Boyle, LaBrie, Froidevaux, \& Witkovic, 2016).

Beside communication with and observation of referent others (offline and online), media content contributes to perceptions about the prevalence of and attitude toward a behavior by presenting individuals who are perceived as similar to oneself and members of the reference group (Geber \& Hefner, 2019; Mead et al., 2014; Tankard \& Paluck, 2016). Bandura (2009) applied social cognitive theory to mass communication stating that media content might promote social diffusion of new styles of behavior by informing, enabling, motivating, and guiding recipients. Comparably, cultivation theory posits that long-term, frequent exposure to television encourages viewers to perceive the real world in ways that reflect the most common messages of the fictional media world (Gerbner \& Gross, 1976; Morgan \& Shanahan, 2010). Thus, by presenting people behaving in certain ways, media messages (fictional, non-fictional, or commercial) shape normative perceptions (Bonfadelli \& Friemel, 2017; Fürst, 2017). Consequently, the observation of behaviors of individuals in media who are perceived as similar to group members results in the belief that the behavior is common within the reference group (perceived descriptive norms). Comparably, the observed reactions, that is, social approval or disapproval in response to the behavior, 
should affect perceived injunctive norms (Geber \& Hefner, 2019). Supporting this argument, a longitudinal study of media effects on youth alcohol consumption from Yanovitzky and Stryker (2001) suggests that news stories on binge drinking affected perceptions of the social acceptability of binge drinking among adolescents and young adults. A further study among college students found that media exposure was correlated with perceptions of higher permissive peer norms regarding sex (Chia \& Gunther, 2006).

To summarize, the communication cross-level link encompasses processes that explain how collective norms are communicatively transferred to normative perceptions. These processes are manifold in today's media environment: via talking with group members, observing social referents' behavior - both online and offline -, and exposure to media content, individuals learn about their referents' behaviors and behavior-related approval and, thus, develop perceptions of descriptive and injunctive norms.

\subsection{Link \#2: Adaptation link}

The second link (\#2, adaptation link) deals with the question of how perceived norms influence individual behavior. This question is subject of all major theories in social norms research (Shulman \& Levine, 2012). According to the focus theory of normative conduct (Cialdini et al., 1990), perceived descriptive norms influence behavior because of people's motivations "to do the right thing" (Rimal \& Lapinski, 2015, p. 397); they promote behaviors by providing an "information-processing advantage" about what may be an effective and adaptive action (Cialdini et al., 1990, p. 1015). Perceived injunctive norms, on the other hand, are thought to influence behavior because of people's intention not to be aberrant and their motivation for affiliation with others (Cialdini et al., 1990). Both norms exert influence on behavior, independently (Park \& Smith, 2007) as well as interactively, enforcing each other (Rimal \& Real, 2005). Meta-analyses provide cumulative evidence for the behavioral relevance of descriptive and injunctive norms, across a variety of behaviors, such as risk behaviors (e.g., smoking, drinking), health behaviors (e.g., exercising, healthy eating), and environmental behavior (e.g., littering, recycling; Manning, 2009; Rhodes, Shulman, \& McClaran, 2020).

In addition to descriptive and injunctive norms, social norms theories consider further cognitive factors that are of behavioral relevance. The theory of planned behavior (Ajzen, 1991) points to perceived behavioral control and attitudes as important behavioral factors (Armitage \& Conner, 2001). The theory of normative social influence (Rimal \& Real, 2005), in contrast, focuses on the conditions under which normative influences are particularly strong, such as group identity and outcome expectations as social mechanisms of normative influence (Rimal \& Real, 2005; for an overview on further moderators: Chung \& Rimal, 2016; Rimal \& Lapinski, 2015). It was, for example, found that perceptions about descriptive norms were particularly influential on college students' drinking behavior when they identified with other students (Rimal \& Real, 2005).

Because of the theoretical and empirical evidence in the tradition of the theory of planned behavior (Ajzen, 1991), normative social influence (Rimal \& Real, 2005), and focus theory of normative conduct (Cialdini et al., 1990) this individual-level link between perceived norms and individual behavior can be regarded as well established.

\subsection{Link \#3: Aggregation link}

Lapinski and Rimal (2005; Rimal \& Lapinski, 2015) also presented important notions on how collective norms relate to individual attributes, that are, behaviors and attitudes. Based on these notions, the third link (\#3, aggregation link) addresses the transition of individual behaviors and attitudes to collective norms and establishes aggregation as the cross-level link (Lazarsfeld \& Menzel, 1965; Liska, 1990).

In contrast to the communication cross-level link (\#1), aggregation is a formal link. It does not imply social interactions like communication and, thus, 
does not add novel social processes to the MANSI. It is a formal rule about how individual attributes have to be combined to yield group attributes (Liska, 1990). According to this rule, the average of group members' behavior or attitudes represent the collective norm, which "signifies the overall social milieu" (Rimal \& Lapinski, 2015, p. 397). Therefore, collective norms have to be considered as "meaningful properties of social units" (Liska, 1990, p. 296) as they - like structural and global properties of collectives - "vary systematically across social units" (Liska, 1990, p. 297) and thus reflect their specificity (Lazarsfeld \& Menzel, 1965). Sedlander and Rimal (2019), for example, created a collective norm of contraception use among adolescents in Ethiopia and Tanzania by aggregating individual contraception use in specific geographic vicinities, enumeration areas, and then removing the individual herself. Mollborn, Domingue, and Boardman (2014a) determined the U.S. high schools' norm against teen pregnancy based on survey data of the National Longitudinal Study of Adolescent Health and found schools' norms to differ significantly. Sedlander et al. (2021) created a more proximal collective norm of contraception use by aggregating participant's chosen social network (up to five people with whom they spend the most time). Such differences in collective norms across schools, communities, or countries reflect important collective-specific attributes that need to be considered in normative influences.

\section{Unfolding the complexity within the MANSI}

To cope with the complexity of individuals' social reality, further aspects have to be taken into account within a multilevel approach to normative social influences (MANSI) that are discussed in current social norms literature. First, individuals are embedded in multiple reference groups; second, these groups comprise different roles relative to normative social influences; and, third, the individuals' environ- ment encompasses more abstract levels in addition to the group level.

\subsection{Multiple reference groups}

People are embedded in various reference groups, ranging from proximal groups (such as close friends, family, or romantic partners) and more distal referent others (such as schoolmates, peers, or colleagues). Research has shown that proximal groups exert stronger normative influence than distal referent others (Woolf, Rimal, \& Sripad, 2014), and that the normative influence depends on perceived proximity to (Paek, 2009; Paek \& Gunther, 2007) and identification with the social group (Neighbors et al., 2010). However, also rather distal groups function as reference groups and exert normative influences (Woolf et al., 2014). Lynch, Coley, Sims, Lombardi, and Mahalik (2015) even demonstrated that multiple sources (parents, friends, schoolmates) might have normative social influences simultaneously and interactively. This underlines the importance of communication processes on social media platforms, such as Facebook or Instagram, where multiple distinct social groups are converging into a single homogeneous unit (e.g., Facebook friends); a phenomenon which is also known as context collapse (Vitak, 2012; Vitak, Blasiola, Patil, \& Litt, 2015; Zillich \& Müller, 2019). Even though not all subgroups of social media networks might equally serve as reference frame regarding a focal behavior (Zillich \& Müller, 2019), the sheer co-presence of various groups in one network heightens the complexity of normative influences that people are potentially exposed to on social media.

\subsection{Multiple social roles}

We also have to take into account that there are various roles within reference groups. Two of them might be particularly relevant with regard to normative social influences: leaders and deviants (Hogg \& Reid, 2006; Schachter, 1951; Tankard \& Paluck, 2016). The idea of normative leaders is related to the concept of social referents (Paluck \& Shepherd, 2012) and opinion leaders (Katz, 
2015; Katz \& Lazarsfeld, 1955). Such leaders are generally "prototypical" in their behaviors and attitudes (Hogg \& Reid, 2006), meaning that their behaviors and attitudes are representative for the group's norms (Weimann, 1994). Because of their prototypicality, leaders are seen as "the best source of information about the group norm" (Hogg \& Reid, 2006, p. 20). For instance, for the case of adolescents' risk behavior, Geber (2019) found that friends who are recognized as advisors have a distinct impact on injunctive normative perceptions, that is, perceptions about the behavior's social approval among friends.

In contrast, deviants are not in line with the group norm. Their deviance in behaviors and attitudes might be the reason why they are "top in the head" (Taylor \& Fiske, 1977, p. 249) and, in consequence, are particularly observed and talked to by other group members (Schachter, 1951; Wesselmann et al., 2014). The consistent finding that people tend to overestimate the permissiveness of risk behaviors (Berkowitz, 2004; Borsari \& Carey, 2003) indicates that deviants might play an important role in shaping normative perceptions (Hogg \& Reid, 2006).

\subsection{Multiple levels}

Beside the group level, the individuals' social environment consists of further levels that increase in their level of abstraction. Patrick et al. (2012, p. 581) developed a "hierarchical norms theory," according to which social groups and associated norms are hierarchically ordered, with smaller and more proximal groups existing within larger and more distal groups. Such analytical levels of collectives and their norms fall on a continuum of micro and macro (Eulau, 1986; Pan \& McLeod, 1991), more specifically, on a continuum from the individual to the group to the culture. Thus, norms do not only refer to proximal and clearly defined reference groups, they are also properties of more abstract collectives, such as societies and cultures (Hechter \& Opp, 2001a) and can exert influences (Fürst, 2017; Patrick et al., 2012). For the case of teen pregnancy norms, for example, Mollborn, Domingue, and Boardman (2014b, p. 1) found that "norms at different levels [such as peer network norms and school norms, the authors] can operate independently of each other, interactively, or in opposition."

\section{Social change within the MANSI}

The MANSI and the above discussed social reality aspects - that is, multiple reference groups, social roles, and levels - allow us to think about norms "as dynamic entities" (Rimal \& Lapinski, 2015, p. 393), developing across time (Lapinski, Kerr, Zhao, \& Shupp, 2017; Liu et al., 2019; Tankard \& Paluck, 2016; also Latané, 1996; Pan \& McLeod, 1991).

\subsection{Norm dynamics}

The MANSI proposes that individuals learn about the norms of their reference group through communication (link \#1) and align their behavior to their normative perceptions (link \#2). Such influences on individual behaviors would result in conformity to the group's codes of conduct at the individual micro level, and, in "the maintenance of the status quo" of the collective norm at the macro level (Pan \& McLeod, 1991, p. 151). The continuing influence of an established norm on behavior and practices over time is referred to as norm maintenance in social norms literature (Legros \& Cislaghi, 2020). However, there are some circumstances and events under which a deviation from the status quo is likely, implying that new norms emerge or existing norms are changed. Following Legros and Cislaghi (2020), norm emergence refers to processes in which a norm comes into being; this involves actions that have already been conducted by some people but that were not yet prevalent and / or socially approved behaviors in a community. Norm change, on the other hand, pertains to processes in which an already established norm ceases to exert influence. Mechanisms underlying these norm dynamics refer to the individual level and group level, as well as external background factors. 


\subsection{Mechanisms of norm dynamics}

At the individual level, reasons for norm emergence and change are linked to the notion that individuals are not solely guided through social influences (Rice, 1993). The theory of planned behavior (Ajzen, 1991), for example, suggests that individuals might not comply to norms because of opposing attitudes or interfering behavioral control perceptions. Additionally, persons are not only subject to influences, but also make purposeful, autonomous choices (Tankard \& Paluck, 2016). To reduce cognitive dissonance (Festinger, 1957), they select like-minded ties (Friemel, 2015; Valente, 2005) and sources of normative information (also referred to as "selective exposure"; Knobloch-Westerwick, 2015). Such selection processes help to understand why some norms and normative information might be avoided and alternatives might be turned to, providing the individual with degrees of freedom in their behavioral choices.

At the group level, mechanisms for norm dynamics are related to the individual's embeddedness in several reference groups, such as school class, friends, and family (Merton \& Rossi, 1968). Given that the norms of these groups are likely to differ with respect to a certain behavior, individuals are exposed to diverging normative influences and thus might not fully and solely adjust their behavior to the norms of a specific group (Holtzman \& Rubinson, 1995; Mollborn et al., 2014b). Second, we consider that a reference group comprises different normative roles (Hogg \& Reid, 2006; Tankard \& Paluck, 2016) who exert diverging normative influences. Contacts with leaders might transport ideas about norms which are in line with collective norms (Geber, 2019; Hogg \& Reid, 2006; Paluck \& Shepherd, 2012); communication with and observations of deviants are likely to lead to normative perceptions that do not align with the group norm (Hogg \& Reid, 2006; Schachter, 1951; Wesselmann et al., 2014). Third, because of the diversity of normative information sources to which people are exposed in their everyday lives (Mead et al., 2014; Tankard \& Paluck, 2016), we expect that individuals might make dif- ferent social inferences with regard to the norms of a specific reference group.

Last, mechanisms for norm dynamics are also linked to external factors, lying beyond the social system. Background conditions might be for example historical (e.g., traditions, customs, and habit; Etzioni, 2000) or ecological and threat-related, such as diseases (Morris, Hong, Chiu, \& Liu, 2015). The COVID-19 pandemic is a good example for such a background factor that heavily affects existing social norms and affords the emergence of new social norms (Rimal \& Storey, 2020). For example, as a consequence of social distancing measures (Friemel \& Geber, 2021), the norm of shaking hands, hugging, or kissing on the cheek when people meet is not socially approved anymore and new ways of greeting have been established (e.g., an elbow bump).

\subsection{Processes of norm dynamics}

The processes of norm emergence and change are tightly linked: An emerging norm can potentially interfere with one that existed before resulting in a modification of the latter, as demonstrated by the example of hugging, hand shaking, and kissing on the cheek during the COVID-19 pandemic (Legros \& Cislaghi, 2020). Both processes can be thought of as a "spiral process" (Pan \& McLeod, 1991, p. 151). The more prevalent and approved a new or modified behavior becomes in a reference group, the more individuals will perceive this as a norm and comply with it. Consequently, the behavior becomes more common and approved in the reference group (Legros \& Cislaghi, 2020). Thus, in a dynamic process (Latané, 1996), collective norms are changing and perceived norms are updated, forming a spiral pattern in which norms develop over time (Tankard \& Paluck, 2016). Following the idea of multiple levels that are nested within and linked to each other (Sallis \& Owen, 2015), such processes spiral not only over time but also over levels and might scale up in social changes at society or cultural level (Smith, Thomas, \& McGarty, 2015). In other words, the norm might first emerge and change in a given group of people and 
then is followed by a new behavior in that group. Then, members of related groups might also adopt the norm, resulting in further social change in the larger society (Legros \& Cislaghi, 2020).

\section{Challenges and further inquiries}

The MANSI organizes theoretical ideas and empirical evidence within a multilevel framework with the aim to inspire future research to go beyond individual-level studying of normative social influences. However, the study of norms at multiple levels faces some challenges and needs further inquiry.

\subsection{Challenges}

The empirical examination of norms at multiple levels requires attention to issues of measurement, study design, and data analysis. The first challenge refers to the measurement of collective norms: As collective norms are not codified (Hechter \& Opp, 2001a, p. xi), measuring them represents "a key challenge" (Lapinski \& Rimal, 2005, pp. 129-130; Rimal \& Lapinski, 2015, p. 396). Some studies refer to aggregates of individuals' self-reports (Costenbader et al., 2019; Geber et al., 2021). Alternatively, studies might refer to observational data at the collective level to acquire information independently from self-assessments and to avoid data collection from every member of the collective. For example, as proposed by Rimal and Lapinski (2015), alcohol sales in a community could serve as a proxy for the collective norm regarding community's alcohol consumption.

The second challenge refers to the causality of normative social influences proposed by the MANSI. Causality assumptions are only testable in longitudinal study designs with measurements at several time points (e.g., Carpenter \& Amaravadi, 2019). For example, the most complex process in the MANSI with regard to the number of time points (i.e., the combination of link \#1 [communication link] and link \#2 [adaptation link]), requires at least three waves to empirically test the underlying causality assumptions (i.e., $t_{1}=$ collective norms, $t_{2}=$ perceived norms, $\mathrm{t}_{3}=$ individual behavior). The more abstract idea presented in the MANSI that the processes of normative social change spirals over time and levels demands even more measurement waves in a longer period.

The third challenge refers to the multilevel structure of data. To analyze independent and interactive effects of variables measured at different levels, specific statistical methods are needed that are able to adequately address the hierarchical structure of the data. Multilevel modeling (for a primer on multilevel modeling: Hayes, 2006) is probably the most common approach to empirically address multilevel data structure (Slater, Snyder, \& Hayes, 2006). However, there are alternative strategies for analysis, such as contextual analysis and simultaneous equation models, to address research questions about the meaning of different levels and corresponding data (for a summary: Pan \& McLeod, 1991).

\subsection{Further inquiries}

Based on the literature on communication in normative social influences, the MANSI establishes communication as the crucial factor that is involved in the transmission of normative attributes from the group to the individual level. However, it does not specify the concrete role that communication plays in analytical and technical terms, for example, whether communication mediates between attributes between both levels (i. e., communication as mediator) or moderates links (i.e., communication as moderator; Southwell \& Yzer, 2007). Thus, the general theoretical understanding of the crucial role of communication with regard to perception formation can be analytically and technically addressed as mediation as well as moderation. For example, it is plausible that a high collective norm of wearing face masks induces talk about this prevention behavior and that this talk results in corresponding normative perceptions on part of the individual (i.e., communication as mediator). Comparably, it is likely that the effect of a high collective face mask norm 
on perceived norms is strengthened when group members have conversations about face masks (i.e., communication as moderator). Specified hypotheses should be formulated and corresponding data analysis approaches should be applied in view of the concrete study's research questions and the associated state of research.

Future research should also address the question as to whether the MANSI equally applies to different behaviors. The attribute-centered approach (Rimal, Lapinski, Turner, \& Smith, 2011) proposes that certain behavioral attributes make a difference regarding the behavior's susceptibility to normative social influences, most importantly the privacy of a behavior (Edberg \& Krieger, 2020). The privacy attribute is particularly relevant with respect to the communicative cross-level links within the MANSI. If a behavior is enacted privately, processes of normative perception building are unlikely. However, social media constitute a platform to present one's behavior to others (e.g., by sharing, liking, and commenting media content; Ellison \& boyd, 2013; Johnson \& Ranzini, 2018) and, thus, afford visibility (Treem \& Leonardi, 2012; also Flanagin, 2017). Consequently, the privacy of a behavior is no longer exclusively an attribute of the behavior but in great parts and in first instance a decision of the individual and this decision, in turn, might depend on affordances of social media platforms and the imagined audiences on these platforms (Litt \& Hargittai, 2016). Having said this, the decision of sharing behaviors and attitudes online itself is likely to be subject to normative influences and to depend on social norms that regulate self-disclosure (Masur, DiFranzo, \& Bazarova, 2021; Zillich \& Müller, 2019). The meaning of behavioral attributes with respect to normative social influences, especially in the light of the digitalization, requires further inquiry.

\section{Conclusion}

This article presents a multilevel approach to normative social influences (MANSI) with communication as the crucial cross-level link. This multilevel approach is especially appropriate with regard to normative social influences because norms are group-phenomena influencing individual behavior (Mollborn et al., 2014a; Rimal \& Lapinski, 2015). This inherent group-individual-tension within the norm concept has been addressed in the MANSI by conceptualizing norms as communicative phenomena (Geber \& Hefner, 2019) and establishing communication as crucial cross-level link. Rooted in different reference groups and influenced by external background events (e.g., a pandemic), these communication processes may induce new norms and changes in norms over time. Our mission in creating the MANSI is to inspire future research and communication campaigns to go beyond individual-level approaches to cope with the complexity of the social reality and to address individual behavior more effectively.

\section{Conflict of interest}

The authors declare no conflict of interests.

\section{References}

Ajzen, I. (1991). The theory of planned behavior. Organizational Behavior and Human Decision Processes, 50(2), 179-211. https:// doi.org/10.1016/0749-5978(91)90020-T

Armitage, C. J., \& Conner, M. (2001). Efficacy of the theory of planned behaviour: A meta-analytic review. British Journal of Social Psychology, 40(4), 471-499. https://doi. org/10.1348/014466601164939

Bandura, A. (1986). Social foundations of thought and action: A social cognitive theo$r y$. Englewood Cliffs, NJ: Prentice-Hall.

Bandura, A. (2009). A social cognitive theory of mass communication. In J. Bryant \& M. B. Oliver (Eds.), Media effects: Advances in theory and research (3rd ed., pp. 94-124). New York, NY: Routledge.

Berger, C. R. (2008). Interpersonal communication. In W. Donsbach (Ed.), The international encyclopedia of communication (pp. 2473-2486). Oxford, UK: Blackwell. 
Berkowitz, A. D. (2004). The social norms approach: Theory, research, and annotated bibliography. Retrieved from http://www. alanberkowitz.com/articles/social_norms. pdf

Beullens, K., \& Vandenbosch, L. (2016). A conditional process analysis on the relationship between the use of social networking sites, attitudes, peer norms, and adolescents' intentions to consume alcohol. Media Psychology, 19(2), 310-333. https:// doi.org/10.1080/15213269.2015.1049275

Bicchieri, C. (2005). The grammar of society. Cambridge, UK: Cambridge University Press. https://doi.org/10.1017/ CBO9780511616037

Bonfadelli, H., \& Friemel, T. N. (2017). Medienwirkungsforschung [Media effects research] (6th ed.). Konstanz, Germany: UVK.

Borsari, B., \& Carey, K. B. (2003). Descriptive and injunctive norms in college drinking: A meta-analytic integration. Journal of Studies on Alcohol, 64(3), 331-341. https:// doi.org/10.15288/jsa.2003.64.331

Boyle, S. C., LaBrie, J. W., Froidevaux, N. M., \& Witkovic, Y. D. (2016). Different digital paths to the keg? How exposure to peers' alcohol-related social media content influences drinking among male and female first-year college students. Addictive Behaviors, 57, 21-29. https://doi. org/10.1016/j.addbeh.2016.01.011

Burgoon, J. K., \& Buller, D. B. (1996). Interpersonal deception theory. Communication Theory, 6(3), 311-328. https://doi. org/10.1111/j.1468-2885.1996.tb00132.x

Carbonara, E. (2017). Law and social norms. In F. Parisi (Ed.), The Oxford handbook of law and economics (pp. 466-482). Oxford, UK: Oxford University Press.

Carcioppolo, N., \& Jensen, J. D. (2012). Perceived historical drinking norms and current drinking behavior: Using the theory of normative social behavior as a framework for assessment. Health Communication, 27(8), 766-775. https://doi.org/10.1080/10 410236.2011.640973

Carpenter, C. J., \& Amaravadi, C. S. (2019). A big data approach to assessing the impact of social norms: Reporting one's exercise to a social media audience. Communication Research, 46(2), 236-249. https://doi. org/10.1177/0093650216657776
Chia, S. C., \& Gunther, A. C. (2006). How media contribute to misperceptions of social norms about sex. Mass Communication and Society, 9(3), 301-320. https://doi. org/10.1207/s15327825mcs0903_3

Chung, A., \& Rimal, R. N. (2016). Social norms: A review. Review of Communication Research, 4, 1-28. Retrieved from https:// www.rcommunicationr.org/index.php/ rcr/article/view/18

Cialdini, R. B., Reno, R. R., \& Kallgren, C. A. (1990). A focus theory of normative conduct: Recycling the concept of norms to reduce littering in public places. Journal of Personality and Social Psychology, 58(6), 1015-1026. https://doi.org/10.1037/00223514.58.6.1015

Coleman, J. S. (1986a). Micro foundations and macrosocial theory. In S. Lindenberg, J. S. Coleman, \& S. Nowak (Eds.), Approaches to social theory (pp. 345-363). New York, NY: Russell Sage Foundation.

Coleman, J. S. (1986b). Social theory, social research, and a theory of action. American Journal of Sociology, 91(6), 1309-1335.

Costenbader, E., Cislaghi, B., Clark, C. J., Hinson, L., Lenzi, R., McCarraher, D. R., ... Stefanik, L. (2019). Social norms measurement: Catching up with programs and moving the field forward. The Journal of Adolescent Health, 64(4S), S4-S6. https:// doi.org/10.1016/j.jadohealth.2019.01.001

Deutsch, M., \& Gerard, H. B. (1955). A study of normative and informational social influences upon individual judgment. Journal of Abnormal and Social Psychology, 51(3), 629-636. https://doi.org/10.1037/ h0046408

Edberg, M., \& Krieger, L. (2020). Recontextualizing the social norms construct as applied to health promotion. SSM - Population Health, 10, 1-9. https://doi.org/10.1016/j. ssmph.2020.100560

Ellison, N. B., \& boyd, d. m. (2013). Sociality through social network sites. In W. H. Dutton (Ed.), The Oxford handbook of Internet studies (1st ed., pp. 151-172). Oxford, UK: Oxford University Press.

Etzioni, A. (2000). Social norms: Internalization, persuasion, and history. Law \& Society Review, 34(1), 157-178. https://doi. org/10.2307/3115119 
Eulau, H. (1986). Politics, self, and society: A theme and variations. Cambridge, MA: Harvard University Press.

Festinger, L. (1957). A theory of cognitive dissonance. Stanford, CA: Stanford University Press.

Fine, G. A. (2001). Enacting norms: Mushrooming and the culture of expectations and explanations. In M. Hechter \& K.-D. Opp (Eds.), Social norms (pp. 139-164). New York, NY: Russell Sage Foundation.

Flanagin, A. J. (2017). Online social influence and the convergence of mass and interpersonal communication. Human Communication Research, 43(4), 450-463. https:// doi.org/10.1111/hcre.12116

Friemel, T. N. (2015). Influence versus selection: A network perspective on opinion leadership. International Journal of Communication, 9, 1002-1022. Retrieved from https://ijoc.org/index.php/ijoc/article/ view/2806/1349

Friemel, T. N., \& Geber, S. (2021). Social distancing during the COVID-19 pandemic in Switzerland: Health protective behavior in the context of communication and perceptions of efficacy, norms, and threat. Health Communication. Advance online publication. https://doi.org/10.1080/1041 0236.2021.1976360

Fürst, S. (2017). Die Etablierung des Internets als Self-Fulfilling Prophecy? Zur Rolle der öffentlichen Kommunikation bei der Diffusion neuer Medien [The establishment of the Internet as a self-fulfilling prophecy? On the role of public communication in the diffusion of new media]. medien \& zeit, 32(2), 43-55. Retrieved from https:// medienundzeit.at/wp-content/uploads/2017/05/mz-2-2017-digital.pdf

Geber, S. (2019). Exploring normative leadership: An egocentric network approach to friends' norm-signaling relevance. International Journal of Communication, 13, 4198-4218. Retrieved from https://ijoc.org/index.php/ijoc/article/ view/11037/2778

Geber, S., Baumann, E., Czerwinski, F., \& Klimmt, C. (2021). The effects of social norms among peer groups on risk behavior: A multilevel approach to differentiate perceived and collective norms. Communica- tion Research, 48(3), 319-345. https:// doi. org $/ 10.1177 / 0093650218824213$

Geber, S., Baumann, E., \& Klimmt, C. (2019). Where do norms come from? Peer communication as a factor in normative social influences on risk behavior. Communication Research, 46(5), 708-730. https://doi. org/10.1177/0093650217718656

Geber, S., \& Hefner, D. (2019). Social norms as communicative phenomena: A communication perspective on the theory of normative social behavior. Studies in Communication and Media, 8(1), 6-28. https:// doi.org/10.5771/2192-4007-2019-1-6

Gerbner, G., \& Gross, L. (1976). Living with television: The violence profile. Journal of Communication, 26(2), 172-199. https://doi.org/10.1111/j.1460-2466.1976. tb01397.x

Geusens, F., Bigman-Galimore, C. A., \& Beullens, K. (2020). A cross-cultural comparison of the processes underlying the associations between sharing of and exposure to alcohol references and drinking intentions. New $\mathrm{Me}$ dia \& Society, 22(1), 49-69. https://doi. org/10.1177/1461444819860057

Guadagno, R. E., Muscanell, N. L., Rice, L. M., \& Roberts, N. (2013). Social influence online: The impact of social validation and likability on compliance. Psychology of Popular Media Culture, 2(1), 51-60. https://doi. org/10.1037/a0030592

Haim, M., Kümpel, A. S., \& Brosius, H.-B. (2018). Popularity cues in online media: A review of conceptualizations, operationalizations, and general effects. Studies in Communication and Media, 7(2), 186-207. https://dx.doi.org/10.5771/2192-40072018-2-58

Hayes, A. F. (2006). A primer on multilevel modeling. Human Communication Research, 32(4), 385-410. https://doi.org/10.1111/ j.1468-2958.2006.00281.x

Hechter, M., \& Opp, K.-D. (2001a). Introduction. In M. Hechter \& K.-D. Opp (Eds.), Social norms (pp. xi-xx). New York, NY: Russell Sage Foundation.

Hechter, M., \& Opp, K.-D. (Eds.). (2001b). Social norms. New York, NY: Russell Sage Foundation.

Hendriks, H., Scholz, C., Larsen, H., Bruijn, G.-J. de, \& van den Putte, B. (2021). In- 
tervening through conversations: How instructions influence conversational valence and binge drinking determinants. Health Communication, 36(6), 782-788. https://doi.org/10.1080/10410236.2020.1 712524

Hogg, M. A., \& Reid, S. A. (2006). Social identity, self-categorization, and the communication of group norms. Communication Theory, 16(1), 7-30. https://doi.org/10.1111/ j.1468-2885.2006.00003.x

Holtzman, D., \& Rubinson, R. (1995). Parent and peer communication effects on AIDS-related behavior among U.S. high school students. Family Planning Perspectives, 27(6), 235-240. https://doi. org/10.2307/2136175

Johnson, B. K., \& Ranzini, G. (2018). Click here to look clever: Self-presentation via selective sharing of music and film on social media. Computers in Human Behavior, 82, 148-158. https://doi.org/10.1016/j. chb.2018.01.008

Kashima, Y., Wilson, S., Lusher, D., Pearson, L. J., \& Pearson, C. (2013). The acquisition of perceived descriptive norms as social category learning in social networks. Social Networks, 35(4), 711-719. https://doi. org/10.1016/j.socnet.2013.06.002

Katz, E. (2015). Where are opinion leaders leading us? Commentary. International Journal of Communication, 9, 1023-1028. Retrieved from https://ijoc.org/index.php/ ijoc/article/view/3699/1348

Katz, E., \& Lazarsfeld, P. F. (1955). Personal influence: The part played by people in the flow of mass communications. New York, NY: Free Press.

Knobloch-Westerwick, S. (2015). The selective exposure self- and affect-management (SESAM) model. Communication Research, 42(7), 959-985. https://doi. org/10.1177/0093650214539173

Lapinski, M. K., Kerr, J. M., Zhao, J., \& Shupp, R. S. (2017). Social norms, behavioral payment programs, and cooperative behaviors: Toward a theory of financial incentives in normative systems. Human Communication Research, 43(1), 148-171. https://doi.org/10.1111/hcre.12099

Lapinski, M. K., \& Rimal, R. N. (2005). An explication of social norms. Communica- tion Theory, 15(2), 127-147. https://doi. org/10.1111/j.1468-2885.2005.tb00329.x

Latané, B. (1996). Dynamic social impact: The creation of culture by communication. Journal of Communication, 46(4), 13-25. https://doi.org/10.1111/j.1460-2466.1996. tb01501.x

Lazarsfeld, P. F., \& Menzel, H. (1965). On the relations between individual and collective properties. In A. Etzioni (Ed.), Reader on complex organizations (pp. 422-440). New York, NY: Holt, Rinehart and Winston.

Legros, S., \& Cislaghi, B. (2020). Mapping the social-norms literature: An overview of reviews. Perspectives on Psychological Science, 15(1), 62-80. https://doi. org/10.1177/1745691619866455

Liska, A. E. (1990). The significance of aggregate dependent variables and contextual independent variables for linking macro and micro theories. Social Psychology Quarterly, 53(4), 292-301. https://doi. org/10.2307/2786735

Litt, D. M., \& Stock, M. L. (2011). Adolescent alcohol-related risk cognitions: The roles of social norms and social networking sites. Psychology of Addictive Behaviors, 25(4), 708-713. https://doi.org/10.1037/ a0024226

Litt, E., \& Hargittai, E. (2016). The imagined audience on social network sites. Social Media + Society, 2(1), 1-12. https://doi. org/10.1177/2056305116633482

Liu, J., Siegel, L., Gibson, L. A., Kim, Y., Binns, S., Emery, S., \& Hornik, R. C. (2019). Toward an aggregate, implicit, and dynamic model of norm formation: Capturing large-scale media representations of dynamic descriptive norms through automated and crowdsourced content analysis. Journal of Communication, 69(6), 563-588. https:// doi.org/10.1093/joc/jqz033

Lynch, A. D., Coley, R. L., Sims, J., Lombardi, C. M., \& Mahalik, J. R. (2015). Direct and interactive effects of parent, friend and schoolmate drinking on alcohol use trajectories. Psychology \& Health, 30(10), 1183-1205. https://doi.org/10.1080/08870 446.2015.1040017

Manning, M. (2009). The effects of subjective norms on behaviour in the theory of planned behaviour: A meta-analysis. The British Journal of Social Psy- 
chology, 48(4), 649-705. https://doi. org/10.1348/014466608X393136

Masur, P. K., DiFranzo, D., \& Bazarova, N. N. (2021). Behavioral contagion on social media: Effects of social norms, design interventions, and critical media literacy on self-disclosure. PloS One, 16(7), 1-20. https://doi.org/10.1371/journal. pone. 0254670

Mead, E. L., Rimal, R. N., Ferrence, R., \& Cohen, J. E. (2014). Understanding the sources of normative influence on behavior: The example of tobacco. Social Science \& Medicine, 115, 139-143. https://doi. org/10.1016/j.socscimed.2014.05.030

Merton, R. K., \& Rossi, A. S. (1968). Contributions to the theory of reference group behavior. In R. K. Merton (Ed.), Social theory and social structures (pp. 279-334). New York, NY: Free Press of Glencoe.

Mollborn, S., Domingue, B. W., \& Boardman, J. D. (2014a). Norms as group-level constructs: Investigating school-level teen pregnancy norms and behaviors. Social Forces, 93(1), 241-267. https://doi. org $/ 10.1093 /$ sf/sou063

Mollborn, S., Domingue, B. W., \& Boardman, J. D. (2014b). Understanding multiple levels of norms about teen pregnancy and their relationships to teens' sexual behaviors. Advances in Life Course Research, 20, 1-15. https://doi.org/10.1016/j.alcr.2013.12.004

Morgan, M., \& Shanahan, J. (2010). The state of cultivation. Journal of Broadcasting \& Electronic Media, 54(2), 337-355. https:// doi.org/10.1080/08838151003735018

Morris, M. W., Hong, Y., Chiu, C., \& Liu, Z. (2015). Normology: Integrating insights about social norms to understand cultural dynamics. Organizational Behavior and Human Decision Processes, 129, 1-13. https://doi.org/10.1016/j.obhdp.2015.03.001

Nagler, R. H. (2017). Measurement of media exposure. In J. Matthes (Ed.), The international encyclopedia of communication research methods (pp. 1-21). Hoboken, NJ: John Wiley \& Sons, Inc. https://doi. org/10.1002/9781118901731.iecrm0144

Neighbors, C., LaBrie, J. W., Hummer, J. F., Lewis, M. A., Lee, C. M., Desai, S., ... Larimer, M. E. (2010). Group identification as a moderator of the relationship between perceived social norms and alcohol consumption. Psychology of Addictive Behaviors, 24(3), 522-528. https://doi. org/10.1037/a0019944

Opp, K.-D. (2011). Modeling micro-macro relationships: Problems and solutions. The Journal of Mathematical Sociology, 35(1-3), 209-234. https://doi.org/10.1080/ 0022250X.2010.532257

Paek, H.-J. (2009). Differential effects of different peers: Further evidence of the peer proximity thesis in perceived peer influence on college students' smoking. Journal of Communication, 59(3), 434-455. https://doi.org/10.1111/j.14602466.2009.01423.x

Paek, H.-J., \& Gunther, A. C. (2007). How peer proximity moderates indirect media influence on adolescent smoking. Communication Research, 34(4), 407-432. https://doi. org/10.1177/0093650207302785

Paluck, E. L., \& Shepherd, H. (2012). The salience of social referents: A field experiment on collective norms and harassment behavior in a school social network. Journal of Personality and Social Psychology, 103(6), 899-915. https://doi.org/10.1037/ a0030015

Pan, Z., \& McLeod, J. M. (1991). Multilevel analysis in mass communication research. Communication Research, 18(2), 140-173. https://doi. org/10.1177/009365091018002002

Park, H. S., \& Smith, S. W. (2007). Distinctiveness and influence of subjective norms, personal descriptive and injunctive norms, and societal descriptive and injunctive norms on behavioral intent: A case of two behaviors critical to organ donation. Human Communication Research, 33(2), 194-218. https://doi.org/10.1111/j.14682958.2007.00296.x

Parsons, T. (1951). Illness and the role of the physician: A sociological perspective. The American Journal of Orthopsychiatry, 21(3), 452-460. https://doi. org/10.1111/j.1939-0025.1951.tb00003.x

Patrick, M. E., Neighbors, C., \& Lee, C. M. (2012). A hierarchy of $21^{\text {st }}$ birthday drinking norms. Journal of College Student Development, 53(4), 581-585. https://doi. org $/ 10.1353 / \operatorname{csd} .2012 .0060$ 
Pempek, T. A., Yermolayeva, Y. A., \& Calvert, S. L. (2009). College students' social networking experiences on Facebook. Journal of Applied Developmental Psychology, 30(3), 227-238. https://doi.org/10.1016/j.appdev.2008.12.010

Perkins, H. W. (2002). Social norms and the prevention of alcohol misuse in collegiate contexts. Journal of Studies on Alcohol, Supplement14, 164-172. https://doi. org/10.15288/jsas.2002.s14.164

Perkins, H. W., \& Berkowitz, A. D. (1986). Perceiving the community norms of alcohol use among students: Some research implications for campus alcohol education programming. Substance Use \& Misuse, 21(9-10), 961-976. https://doi. org/10.3109/10826088609077249

Porten-Chée, P., Hassler, J., Jost, P., Eilders, C., \& Maurer, M. (2018). Popularity cues in online media: Theoretical and methodological perspectives. Studies in Communication and Media, 7(2), 208-230. https://doi. org/10.5771/2192-4007-2018-2-80

Raub, W., Buskens, V., \& van Assen, M. A. L. M. (2011). Micro-macro links and microfoundations in sociology. The Journal of Mathematical Sociology, 35(1-3), 1-25. https:// doi.org/10.1080/0022250X.2010.532263

Real, K., \& Rimal, R. N. (2007). Friends talk to friends about drinking: Exploring the role of peer communication in the theory of normative social behavior. Health Communication, 22(2), 169-180. https://doi. org/10.1080/10410230701454254

Rhodes, N., Shulman, H. C., \& McClaran, N. (2020). Changing norms: A meta-analytic integration of research on social norms appeals. Human Communication Research, 46(2-3), 161-191. https://doi. org $/ 10.1093 / \mathrm{hcr} / \mathrm{hqz} 023$

Rice, R. E. (1993). Using network concepts to clarify sources and mechanisms of social influence. In W. Richards \& G. Barnett (Eds.), Progress in communication sciences: Advances in communication network analysis (pp. 43-52). Norwood, NJ: Ablex.

Rimal, R. N., \& Lapinski, M. K. (2015). A re-explication of social norms, ten years later. Communication Theory, 25(4), 393-409. https://doi.org/10.1111/comt.12080

Rimal, R. N., Lapinski, M. K., Turner, M. M., \& Smith, K. C. (2011). The attribute-centered approach for understanding health behaviors: Initial ideas and future research directions. Studies in Communication Sciences (SComS), 11(1), 15-34.

Rimal, R. N., \& Real, K. (2003). Understanding the influence of perceived norms on behaviors. Communication Theory, 13(2), 184-203. https://doi. org/10.1111/j.1468-2885.2003.tb00288.x

Rimal, R. N., \& Real, K. (2005). How behaviors are influenced by perceived norms: A test of the theory of normative social behavior. Communication Research, 32(3), 389-414. https://doi. org/10.1177/0093650205275385

Rimal, R. N., \& Storey, J. D. (2020). Construction of meaning during a pandemic: The forgotten role of social norms. Health Communication, 35(14), 1732-1734. https:// doi.org/10.1080/10410236.2020.1838091

Sallis, J. F., \& Owen, N. (2015). Ecological models of health behavior. In K. Glanz, B. K. Rimer, \& K. Viswanath (Eds.), Health behavior: Theory, research, and practice (5th ed., pp. 43-64). San Francisco, CA: Jossey-Bass.

Saxena, D. (1971). The "reference group" concept. Social Science, 46(3), 155-164.

Schachter, S. (1951). Deviation, rejection, and communication. The Journal of Abnormal and Social Psychology, 46(2), 190-207. https://doi.org/10.1037/h0062326

Sedlander, E., Bingenheimer, J. B., Lahiri, S., Thiongo, M., Gichangi, P., Munar, W., \& Rimal, R. N. (2021). Does the belief that contraceptive use causes infertility actually affect use? Findings from a social network study in Kenya. Studies in Family Planning, 52(3), 343-359. https://doi. org/10.1111/sifp. 12157

Sedlander, E., Long, M. W., Mohanty, S., Munjral, A., Bingenheimer, J. B., Yilma, H., \& Rimal, R. N. (2020). Moving beyond individual barriers and identifying multi-level strategies to reduce anemia in Odisha India. BMC Public Health, 20, 1-16. https:// doi.org/10.1186/s12889-020-08574-z

Sedlander, E., \& Rimal, R. N. (2019). Beyond individual-level theorizing in social norms research: How collective norms and media access affect adolescents' use of contraception. The Journal of Adolescent Health, 
64(4S), S31-S36. https://doi.org/10.1016/j. jadohealth.2018.12.020

Shepherd, H. (2017). The structure of perception: How networks shape ideas of norms. Sociological Forum, 32(1), 72-93. https:// doi.org/10.1111/socf.12317

Sherif, M. (1936). The psychology of social norms. New York, NY: Harper \& Brothers.

Sherif, M. (1953). The concept of reference groups in human relations. In M. Sherif \& M. O. Wilson (Eds.), Group relations at the crossroads (pp. 203-231). New York, NY: Harper.

Shulman, H. C., \& Levine, T. R. (2012). Exploring social norms as a group-level phenomenon: Do political participation norms exist and influence political participation on college campuses? Journal of Communication, 62(3), 532-552. https://doi. org/10.1111/j.1460-2466.2012.01642.x

Shulman, H. C., Rhodes, N., Davidson, E., Ralston, R., Borghetti, L., \& Morr, L. (2017). The state of the field of social norms research. International Journal of Communication, 11, 1192-1213. Retrieved from https://ijoc.org/index.php/ijoc/article/ view/6055/1966

Slater, M. D., Snyder, L., \& Hayes, A. F. (2006). Thinking and modeling at multiple levels: The potential contribution of multilevel modeling to communication theory and research. Human Communication Research, 32(4), 375-384. https://doi. org/10.1111/j.1468-2958.2006.00292.x

Smith, L. G. E., Thomas, E. F., \& McGarty, C. (2015). "We must be the change we want to see in the world": Integrating norms and identities through social interaction. Political Psychology, 36(5), 543-557. https:// doi.org/10.1111/pops.12180

Southwell, B. G., \&Yzer, M. C. (2007). The roles of interpersonal communication in mass media campaigns. Annals of the International Communication Association, 31(1), 420-462. https://doi.org/10.1080/2380898 5.2007.11679072

Tankard, M. E., \& Paluck, E. L. (2016). Norm perception as a vehicle for social change. Social Issues and Policy Review, 10(1), 181211. https://doi.org/10.1111/sipr.12022

Taylor, S. E., \& Fiske, S. T. (1977). Salience, attention, and attribution: Top of the head phenomena. Advances in Experimental
Social Psychology, 11, 249-288. https://doi. org/10.1016/S0065-2601(08)60009-X

Treem, J. W., \& Leonardi, P. M. (2012). Social media use in organizations: Exploring the affordances of visibility, editability, persistence, and association. Communication Yearbook, 36, 143-189. https://doi org/10.2139/ssrn.2129853

Valente, T. W. (2005). Network models and methods for studying the diffusion of innovations. In P. J. Carrington, J. Scott, \& S. Wasserman (Eds.), Models and methods in social network analysis. Structural analysis in the social sciences (pp. 98-116). Cambridge, MA: Cambridge University Press. https://doi.org/10.1017/ CBO9780511811395.006

Vitak, J. (2012). The impact of context collapse and privacy on social network site disclosures. Journal of Broadcasting \& Electronic Media, 56(4), 451-470. https://doi.org/10.1 080/08838151.2012.732140

Vitak, J., Blasiola, S., Patil, S., \& Litt, E. (2015). Balancing audience and privacy tensions on social network sites. International Journal of Communication, 9, 1485-1504. Retrieved from https://ijoc.org/index. $\mathrm{php} / \mathrm{ijoc} / \mathrm{article} / \mathrm{view} / 3208 / 1382$

Walther, J. B., Carr, C. T., Choi, S., DeAndrea, D. C., Kim, J., Tong, S. T., \& van der Heide, B. (2010). Interaction of interpersonal, peer, and media influence sources online: A research agenda for technology convergence. In Z. Papacharissi (Ed.), A networked self: Identity, community and culture on social network sites (pp. 17-38). New York, NY: Routledge.

Weimann, G. (1994). The influentials: People who influence people. Albany, NY: State University of New York Press.

Wesselmann, E. D., Williams, K. D., Pryor, J. B., Eichler, F. A., Gill, D. M., \& Hogue, J. D. (2014). Revisiting Schachter's research on rejection, deviance, and communication (1951). Social Psychology, 45(3), 164-169. https://doi.org/10.1027/1864-9335/ a000180

Woolf, J., Rimal, R. N., \& Sripad, P. (2014). Understanding the influence of proximal networks on high school athletes' intentions to use androgenic anabolic steroids. Journal of Sport Management, 28(1), 8-20. https://doi.org/10.1123/jsm.2013-0046 
Yanovitzky, I., \& Rimal, R. N. (2006). Communication and normative influence: An introduction to the special issue. Communication Theory, 16(1), 1-6. https://doi. $\operatorname{org} / 10.1111 /$ j.1468-2885.2006.00002.x

Yanovitzky, I., \& Stryker, J. O. (2001). Mass media, social norms, and health promotion efforts. A longitudinal study of media effects on youth binge drinking. Communication Research, 28(2), 208-239. https:// doi.org/10.1177/009365001028002004

Young, H. P. (1998). Social norms and economic welfare. European Economic Review,
42(3-5), 821-830. https://doi.org/10.1016/ S0014-2921(97)00138-4

Zillich, A. F., \& Müller, K. F. (2019). Norms as regulating factors for self-disclosure in a collapsed context: Norm orientation among referent others on Facebook. International Journal of Communication, 13, 2632-2651. Retrieved from https://ijoc.org/index.php/ijoc/article/ view/10943/2685 